\title{
Fertility Intentions across Immigrant Generations in Sweden* Do Patterns of Adaptation Differ by Gender and Origin?
}

\section{Erik Carlsson}

\begin{abstract}
In being representative of individuals' demographic value orientations, fertility preferences provide information about immigrants' adaptation to family formation patterns in the destination country at a deeper, ideational level than actual fertility does. Using data from Wave 1 of the Swedish GGS from 2012/2013 $(n=3,932)$, this study compares the first, 1.5 , and second generations with either one or two foreign-born parent(s) to Swedes without an immigrant background by gender and across origins. Binary logistic regression is used to compare the propensity to state a positive fertility intention, and partial proportional odds models are used to analyse differences across four ordinal intention categories (definitely/probably yes/no). Results show a general tendency towards convergence from the relatively positive intentions of the first generation to levels closer to non-immigrants in later generations, although complete convergence is only found for the second generation with one foreign-born parent. There are gender differences, with women being similar to non-immigrants by the 1.5 generation, while there is no clear intergenerational trend for men. Among origin groups, convergence is evident among Eastern Europeans and "other non-Europeans", while Westerners already are similar to nonimmigrants in the first generation, and Middle Easterners/North Africans display no clear intergenerational trend. This study contributes to the understanding of immigrant fertility by showing that there often is intergenerational adaptation at the ideational (i.e. preference) level, that the pace and extent of convergence vary by gender and across origins, and that group-level patterns found for fertility intentions do not always match those found in earlier research on fertility behaviour.
\end{abstract}

Keywords: Fertility intentions · Immigrants · Second generation 1.5 generation Swedish Generations · Gender Survey

\footnotetext{
This article belongs to a special issue on migrant fertility.
} 


\section{Introduction}

Immigrant fertility is a topic of sustained research interest in Europe, with work on first-generation patterns (see Kulu/González-Ferrer 2014 for an overview) being complemented by a growing body of literature dealing with second-generation childbearing (e.g. Milewski 2011; Scott/Stanfors 2011; Krapf/Wolf 2015; Andersson et al. 2017; Kulu et al. 2017; Pailhé 2017; Van Landschoot et al. 2017; Guarin Rojas et al. 2018). An intergenerational perspective on immigrant fertility is particularly informative, since changes from the first to subsequent generations are indicative of immigrant communities' longer-term integration into the demographic context of the destination country (e.g. De Valk/Milewski 2011; Milewski 2011). Earlier research indeed shows that fertility behaviour often tends to approach non-immigrant patterns over immigrant generations, indicating that adaptation to the destination country is an important force in shaping childbearing patterns among immigrant descendants.

The aim of this study is to analyse to what extent this trend of intergenerational convergence found for actual fertility also applies to fertility intentions. The gap between preferences and actual fertility that is often found at both the aggregate and individual level in post-transitional societies (e.g. Bongaarts 2001; Goldstein et al. 2003; Liefbroer 2009) clearly shows that the two concepts are not interchangeable. Theoretical models on the association between fertility preferences and outcomes describe how the former are closer to underlying norms and ideology, while the latter are mediated by intervening factors to a larger extent (Miller/Pasta 1995; Ajzen/ Klobas 2013). Thus, only studying fertility outcomes cannot clarify whether behavioural adaptation results from adaptation to the institutional context of the destination country or from adaptation in underlying social norms. In constituting a more direct indicator of an individual's demographic value orientation, fertility preferences therefore contribute an additional, ideational dimension to the understanding of demographic assimilation among immigrants and their descendants (see Holland/ De Valk 2013). Yet despite the potential contribution of studying fertility preferences among immigrants and immigrant descendants to the understanding of their degree of adaptation to the demographic patterns of the destination country, only a small number of studies have so far dealt with the topic (see De Valk 2013; Holland/ De Valk 2013; Kraus/Castro-Martín 2018).

This study analyses how one specific type of fertility preference, namely shortterm parity-progression intentions, varies across immigrant generations in Sweden. ${ }^{1}$ Non-immigrants (defined here as Swedish-born individuals with two Swedish-born parents) are compared to immigrants and immigrant descendants of four generational categories: the first immigrant generation (foreign-born individuals

1 This study distinguishes terminologically between a fertility preference and a fertility intention, where the former is used in a more general sense, while the latter is used to refer to a specific type of fertility preference. See section 2.2 for a discussion of theoretical considerations regarding fertility preferences. 
who immigrated at age 15 or later), the 1.5 generation (foreign-born individuals who immigrated prior to age 15), the second generation (Swedish-born individuals) with two foreign-born parents, and the second generation with one foreign-born parent. $^{2}$ Using data from Wave 1 of the Swedish Generations and Gender Survey from $2012 / 2013$, this study employs binary logistic regression to analyse the propensity to state a positive (as opposed to negative) fertility intention and partial proportional odds models to analyse the propensity to state a more positive intention along a four-category scale (definitely no, probably no, probably yes, and definitely yes). In addition to aggregate-level trends, intergenerational patterns are also analysed separately by gender. This is an important contribution of the present study, since the gender dimension has received little attention in earlier research on immigrant fertility (see Ortensi 2015). As a third analytical step, this study also examines how intergenerational patterns vary by origin (Western, Eastern European, Middle Eastern/North African, and "other non-European") - an important dimension, as earlier studies have found origin to be a central factor in understanding actual fertility among immigrants and immigrant descendants (e.g. Andersson 2004; Milewski 2007, 2010; Scott/Stanfors 2011; Mussino/Strozza 2012; Kulu/Hannemann 2016; Andersson et al. 2017; Kulu et al. 2017; Pailhé 2017).

\section{Background}

\subsection{Fertility behaviour among immigrants and their descendants}

Among the different hypotheses on immigrant fertility proposed in earlier research (e.g. Milewski 2007, 2010; Sobotka 2008; Mussino/Strozza 2012; Baykara-Krumme/ Milewski 2017), the socialisation and adaptation perspectives are most relevant for this study, since they are also applicable to the longer-term, intergenerational effects of migration. Socialisation into the culture of the origin country on the one hand, and adaptation to the culture and institutions of the destination country on the other can be seen as two competing processes that can explain either persistent differences or convergence relative to non-immigrant patterns. Within demographic research, the intergenerational transmission of fertility preferences and behaviour is a well-established phenomenon (e.g. Murphy/Knudsen 2002; Eschelbach 2015). Findings that such linkages are primarily tied to value transmissions rather than socioeconomic continuities (Kolk 2013) indicate that socialisation effects are relevant for analysing fertility in the context of international migration. However, as most immigrants are also exposed to the values and customs as well as the institutional setting of the destination country, there is also reason to expect adaptation.

For the first generation, there is support for both the socialisation (Sobotka 2008; Mussino/Strozza 2012; Cygan-Rehm 2014) and adaptation perspectives in Europe

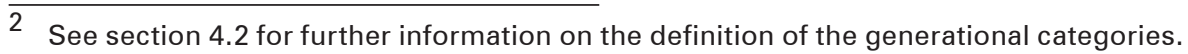


(e.g. Mayer/Riphahn 2000; Milewski 2007, 2010). This also applies to Sweden, where immigrants' cohort fertility at age 40 is on average and for most origin groups very close to the non-immigrant level, while it is lower for immigrants from non-Nordic EU countries and higher for immigrants from non-European low-HDI (Human Development Index) countries (Statistics Sweden 2014). However, first-generation period fertility in Sweden is slightly higher than non-immigrant levels (Statistics Sweden 2014), which may be explained by the observation that migration is often interrelated with other important life course events, such as marriage and childbearing (Andersson 2004; Milewski 2007, 2010). It has been shown that immigrants tend to have fewer children than non-immigrants of the same age at arrival to Sweden, and then close the gap after arrival, thereby driving up period fertility measures (Statistics Sweden 2014). Andersson (2004) finds that most first-generation origin groups in Sweden have higher first and third birth transition rates but lower second birth transition rates compared to non-immigrant Swedes. However, these differences pertain primarily to the first years following immigration, with the high first and third birth transition rates tending to approach non-immigrant levels with time since immigration, while second birth transition rates do not change substantially. Andersson (2004) also shows that these parity-specific transition rates vary considerably between high-fertility origins such as Somalia, Arab countries, Ethiopia, and Vietnam/Indochina, and low-fertility origins such as Iran and various Eastern European countries. Although all groups experience fertility reduction compared to the initial period after immigration to Sweden, immigrants from Muslim and SubSaharan African countries stand out from other origin groups by still having substantially higher transition rates than non-immigrants even after the first five years in Sweden.

Compared to the first generation, the children of immigrants are more likely to have adapted, since they are exposed to destination country patterns during the formative years of childhood and adolescence. Indeed, earlier European research finds that many groups of immigrant descendants, of both European and nonWestern origin, have similar or somewhat lower fertility than non-immigrants in the destination country (e.g. Milewski 2007, 2010; Kulu/Hannemann 2016; Kulu et al. 2017; Van Landschoot et al. 2017; Guarin Rojas et al. 2018). Generally, adaptation is more evident among the second generation than among the 1.5 generation (Scott) Stanfors 2011). However, there are also origin groups that display an alternative pattern, with fertility lying between the first generation and non-immigrants. This pattern of persistent but diminishing differences in relation to non-immigrants across immigrant generations seems to work via the 1.5 generation (see Scott/Stanfors 2011; Krapf/Wolf 2015) and has been found for many different origin groups and in many different European destination countries, including Turks in Germany, the Netherlands, Belgium, and elsewhere (Garssen/Nicolaas 2008; Milewski 2011), Moroccans in the Netherlands and Belgium (Garssen/Nicolaas 2008), Bangladeshis and Pakistanis in the United Kingdom (Coleman/Dubuc 2010), and Middle Easterners in Sweden (Scott/Stanfors 2011). For these origin groups, it seems that the second generation's medium position between the first generation and non-immigrants holds across many different aspects of fertility, such as quantum (Garssen/Nico- 
laas 2008; Coleman/Dubuc 2010), age at first birth (Garssen/Nicolaas 2008), parityspecific transition rates (Milewski 2007, 2010, 2011; Kulu/Hannemann 2016), and ideals about quantum and the age of entry into parenthood (De Valk 2013). These findings suggest that both socialisation and adaptation processes are important in understanding the fertility patterns of these origin groups, a notion that is further supported by Milewski's (2011) finding that first birth transition rates among the Turkish second generation in Europe differ across destination countries, while they are consistently higher than those of non-immigrants. Whether the intermediate position of the second generation of some origins should be interpreted as a step on the path towards full convergence or as indications of an emerging high-fertility subculture will become clearer when the third generation reaches childbearing ages in greater numbers.

Research on the fertility of immigrant descendants in Sweden has produced results that are similar to the rest of Europe. At the aggregate level, it seems that second-generation period fertility is close to, but slightly lower, than that of nonimmigrants (Statistics Sweden 2010; Andersson et al. 2017). While the Nordic-origin second generation is very similar to non-immigrants, the total fertility rate is lower for groups with a parental origin in non-Nordic EU countries or in mediumHDI countries outside Europe (Statistics Sweden 2010). When comparing parityspecific transition rates among different origin groups of the second generation, many groups, including those with a parental origin in high-fertility countries, have similar or lower transition rates to first and second birth but higher transition rates to third birth compared to non-immigrants (Statistics Sweden 2010; Andersson et al. 2017). Among the groups that do not follow this pattern, rates are elevated for the Middle Eastern second generation (Scott/Stanfors 2011), or more specifically for individuals with an origin in Turkey or Arab-majority countries in the Middle East (Andersson et al. 2017), and depressed for the Eastern European second generation (Scott/Stanfors 2011). It is important to distinguish among the second generation between those with two foreign-born parents and those with one foreign-born and one Swedish-born parent, since it has been shown that the latter have first birth transition rates that are closer to non-immigrants, a pattern that is especially evident when it is the mother who is Swedish-born (Scott/Stanfors 2011: 198).

In understanding what high-fertility socialisation might consist of in the European immigrant context, it seems that religion/religiosity and conservative family arrangements are important elements. Kulu and Hannemann (2016) have shown that religiosity is positively associated with higher-order parity transitions for both the first and the second generation in the United Kingdom. Westoff and Frejka (2007) find that Muslim fertility is higher than non-Muslim fertility in most of Europe and that this gap can largely be explained by higher marriage rates among Muslims and by a higher prevalence of conservative family and gender role attitudes. Milewski (2010: 319) suggests that the relatively high fertility of the Turkish-origin second generation in Germany may be explained by conservative characteristics of the Turkish German community: leaving the parental home and getting married often coincide and occur at a young age, there is social pressure to conceive once married, and there is a high frequency of transnational marriages where one of the partners is a 
German national raised by Turkish parents in Germany and the other is a Turkish national raised in Turkey. Conservative family values have also been observed and linked to high-fertility behaviour among the second generation of Pakistani descent in the United Kingdom (Hampshire et al. 2012). An important aspect of socialisation effects on fertility is the influence of parents' childbearing behaviour. In fact, Brinton et al. (2018) find that the most common motivation for stating a specific ideal family size is a wish to replicate the individual's own or their partner's family-of-origin experience. Earlier research on fertility preferences and behaviour among children of immigrants has shown that individuals' number of siblings is an important factor in understanding intergroup differences (e.g. De Valk 2013; Pailhé 2017).

When it comes to immigrant groups with lower fertility than non-immigrants in Sweden, it is not clear to what extent such patterns should be interpreted as expressions of cultural and socialisation differences. On the one hand, findings that the two-child norm is strong in both high- and low-fertility regions within Europe (Sobotka/Beaujouan 2014; Testa 2014) suggest that fertility differences among European countries could be attributed more to institutional than to cultural differences. On the other hand, there are indications from both Sweden (Andersson 2004; Scott) Stanfors 2011) and elsewhere (e.g. Puur et al. 2017) that some immigrant groups with an origin in countries with lower fertility than the destination country maintain low fertility relative to non-immigrants in the destination country in both the first and later immigrant generations. This suggests that factors other than the institutional context play an important role in understanding low fertility within these origin groups. A possible explanation for low immigrant fertility, at least for the first generation and especially in the early years after migration, is that the migration experience can cause disruption in the life course. Such a disruption effect may, for example, appear when migrants are separated from an existing partner or when they experience difficulties in finding a partner in the destination country due to linguistic, cultural, or other barriers. Whether or not the disruption effect can contribute to explaining immigrant fertility is clearly linked to the context in which the migration takes place, which is reflected in the variation across origin groups, destination countries, and reasons for migration that is shown in earlier research. Thus, while Mussino and Strozza (2012) find support for the mechanism, other European studies do not (e.g. Mayer/Riphahn 2000; Andersson 2004; Milewski 2007, 2010; Baykara-Krumme/Milewski 2017). In Sweden, disruption seems to affect primarily female immigrants with an origin either in low- or medium-HDI non-European countries or in European non-EU countries (Persson/Hoem 2014).

Whereas group differences across origin countries have been an important aspect of research on immigrant fertility, less attention has been paid to the potential for gender differences (see Ortensi 2015), with most earlier analysis focusing on women's childbearing experiences. Findings on fertility preferences among the general population indicate that there are no substantial differences between men and women (Berrington 2004; Miettinen/Paajanen 2005; Hartnett 2014; Dommermuth et al. 2015). However, theoretical insights on how minority group status may affect fertility provide reasons to expect gender differences in how fertility preferences change across immigrant generations. Goldscheider's and Uhlenberg's (1969) mi- 
nority group status hypothesis suggests that individuals from disadvantaged population groups must spend relatively high levels of resources on education and their labour market career when seeking to advance their social position, and therefore choose to limit childbearing in order to permit a concentration of resources into the achievement of upward social mobility. Minority groups may also react to perceived disadvantages by emphasizing differences vis-à-vis the majority culture through cultural maintenance and intragroup loyalty, which may be referred to as "reactive ethnicity" (see Rumbaut 2008). This type of coping strategy may have a boosting effect on fertility levels either indirectly through the conservation of traditional family values and gender norms, for example in promoting religion (McQuillan 2004), or directly via explicit attention to achieving increased numerical strength (Courbage 1992; Sahu/Hutter 2012: 530; Varley 2012; Okun 2016, 2017).

It is possible that these two processes affect male and female children of immigrants in Sweden differently, which may in turn produce differences in fertility intentions. Within the second generation, women have better education outcomes than men, in Sweden as well as in other Western destination countries (Fleischmann et al. 2014). Thus, second-generation women have better labour market career prospects than second-generation men and may therefore be more likely to intend to limit childbearing in order to achieve upward social mobility. Having weaker labour market prospects, male children of immigrants might be more likely to choose an alternative family-oriented life course, perhaps as part of a reactive ethnicity. The empirical support for this theory is mixed. Andersson et al. (2017) find that having three or more years of post-secondary education is positively associated with first, second, and third birth transition rates for second-generation women in Sweden. However, Scott and Stanfors (2011) find that polarisation in fertility behaviour within second-generation origin groups (which has also been observed elsewhere, see Kulu/Hannemann 2016; Kulu et al. 2017) is related to the individual's level of education, so that lower-educated second-generation individuals have higher first-birth transition rates than non-immigrants and higher-educated second-generation individuals have lower first-birth transition rates than non-immigrants. This pattern is especially pronounced among women. In Germany, it has been found that higher education is positively associated with second birth transition rates for non-immigrants, while it is negatively associated with first birth transition rates for 1.5 and second-generation women of Turkish origin (Krapf/Wolf 2015).

\subsection{Theoretical considerations on fertility intentions}

The principal contribution of the present study to the research field of immigrant fertility is the incorporation of fertility preferences into the analysis, something that has so far only been done in a small number of studies (see De Valk 2013; Hartnett 2014; Kraus/Castro-Martín 2018). In general, preferences constitute an important aspect of research on fertility in contemporary, developed societies since it is reasonable to assume ideational factors to be central individual-level determinants of fertility in a context where effective birth control methods can prevent unwanted childbearing and advanced assisted reproductive technologies can reduce unwant- 
ed childlessness (see Bongaarts 2001). As earlier work in the field has revealed the complexities of the concept of fertility preferences, a brief summary of some important theoretical considerations is provided below.

To start with, it is meaningful to distinguish terminologically between different types of fertility preferences (e.g. Thomson 2015). The present study deals with short-term parity-progression intentions, i.e. whether or not an individual plans to have a/another child within a specified timeframe. This type of preference may be contrasted to quantum preferences of different types, such as the desired, ideal, expected, or intended number of children, which are usually expressed without a specified timeframe. While desires and ideals represent more of a vision than a plan for future fertility, intentions are relatively concrete and imply a readiness to act. Miller and Pasta (1995) describe a sequential process where childbearing motivations and child-timing attitudes and beliefs of either biological or experiential origin shape desires on quantum and timing, which in turn shape fertility intentions. In the theory of planned behaviour, which is a commonly employed theoretical framework for the study of fertility intentions, background factors at the individual, demographic, and societal level shape beliefs about consequences, social support, and enabling and interfering factors in relation to having a child. These different types of beliefs then shape an individual's attitude toward having a child, their subjective norm for having a child, and their perceived control over having a child, which combine to form an intention to have a child within a specified timeframe (Ajzen/KIobas 2013). The relationship between the different types of preference has also been described as follows: "Desires are 'internal factors', such as motivations, attitudes, and beliefs [and if they] become more manifest, they materialize into intentions, which will in turn be translated into behaviour if conditions are favorable" (Kuhnt et al. 2017: 237).

While earlier research has found that parity-progression intentions do better than quantum preferences in predicting behaviour (see Balbo et al. 2013: 5-6), there is also variation among different types of intentions. Thus, negative intentions are typically more reliable than positive intentions and intentions expressed with a higher degree of certainty tend to be more reliable than intentions expressed with a lesser degree of certainty (e.g. Schoen et al. 1999; Toulemon/Testa 2005; Régnier-Loilier/ Vignoli 2011; Cavalli/Klobas 2013). Similarly, intentions expressed for the near future are more reliable than intentions expressed for the more distant future, at least among childless individuals (Dommermuth et al. 2015). The measure of fertility intentions used here is expressed within a three-year timeframe and may be given as "definitely no", "probably no", "probably yes", or "definitely yes", thus allowing for variation in both the positive/negative and the degree-of-certainty dimensions.

Studying short-term parity-progression intentions rather than longer-term quantum preferences in the immigration context means that attention should be paid to the possibility of short-term effects of the migration experience on fertility, as described by the interrelation-of-events and disruption perspectives on immigrant fertility. 


\subsection{Demographic and socioeconomic factors that may influence fertility intentions}

In addition to mechanisms discussed in section 2.1, such as socialisation, adaptation, interrelation of events, disruption, etc., it is possible that differences in fertility behaviour and intentions between immigrants, immigrant descendants, and nonimmigrants can be explained by differences in the demographic and socioeconomic composition of the groups. Such differences may arise from selection into migration (e.g. Bagavos et al. 2008), origin/destination differences in economic and social development, or integration processes. Earlier studies on actual fertility among immigrants and immigrant descendants often find that controlling for demographic and socioeconomic factors reduces but does not eliminate differences between non-immigrants and high-fertility origin groups (e.g. Milewski 2010; Statistics Sweden 2010; Krapf/Wolf 2015; Kulu/Hannemann 2016; Kulu et al. 2017; Andersson et al. 2017). The set of demographic and socioeconomic factors listed below, i.e. age, parity, partnership status, number of siblings, educational attainment, and labour market status, have been found to influence the formation of fertility preferences and are known to vary among immigrants, children of immigrants, and non-immigrants, which makes them appropriate control variables for the analyses of the present study (see Appendix Table 1 for generational differences in how the sample analysed in this study is distributed across categories).

A positive association between age and the propensity to state a positive shortterm fertility intention has been found in Norway (Dommermuth et al. 2011). There are also findings indicating that the relationship between age and fertility intentions is inversely U-shaped (e.g. Hiekel/Castro-Martín 2014), so that intentions tend to be less positive at younger and older ages and more positive during the prime childbearing ages.

Parity: It has been shown that childless individuals differ from parents in various respects regarding how they form short-term fertility intentions (e.g. Dommermuth et al. 2011). Generally, being at higher parities is associated with less positive intentions in contexts of relatively low fertility, such as Sweden (Balbo/Mills 2011).

Partnership status: Singles are much less likely than individuals who are in a partnership to form positive short-term fertility intentions (e.g. Philipov et al. 2006; Billari et al. 2009). It is likely that differences also exist among different types of partnership. In mainstream Swedish culture, the meaning and function of marriage and cohabitation are similar but not fully equivalent (see Oh/sson-Wijk 2011; Wiik et al. 2009). As many children in Sweden are born to cohabiting parents who then marry at a later stage, it may be expected that cohabitants are more likely to state a positive intention compared to married individuals, who often are at a more advanced stage of their fertility career. Furthermore, it is reasonable to assume that the intentions of individuals in a non-cohabiting union are less positive than those of married and cohabitating individuals. However, the association between partnership status and fertility intentions may vary among population groups in Sweden. It has been shown that partnership dynamics differ considerably among immigrants and immigrant descendants of various origins and non-immigrants in Sweden ( $A n$ - 
dersson et al. 2015), indicating that there is variation in the meaning attached to different unions. Hiekel and Castro-Martín (2014) have shown both that the meaning attached by cohabiters to their union varies considerably among countries, and that such differences in meaning are associated with the propensity to form different types of fertility intentions.

As discussed in section 2.1, an individual's number of siblings is positively associated with both higher quantum preferences (Heiland et al. 2008; Berrington/ Pattaro 2014) and outcomes (Murphy/Knudsen 2002). Studying family size preferences across ethnic groups in the Netherlands, De Valk (2013) finds that intergroup variation can largely be attributed to differences in the number of siblings that an individual grew up with.

While the direction of association between educational attainment and fertility preferences seems to vary between European countries (Régnier-Loilier/Vignoli 2011; Testa 2014), the intended number of children seems to be somewhat higher among the higher educated in Sweden (Testa 2014). Research on fertility behaviour among children of immigrants similarly indicates that the effect of educational attainment varies among countries (Krapf/Wolf 2015, Kulu/Hannemann 2016; Andersson et al. 2017; Pailhé 2017, see also section 2.1 for further discussion).

Labour market status: Berrington and Pattaro (2014) find that unemployment and economic inactivity is associated with uncertainty about intended family size and intentions to remain childless in the United Kingdom. Research on actual fertility in Sweden shows that being established in the labour market is an important prerequisite for having children, both for immigrants and non-immigrants (Andersson/Scott 2005, 2007; Scott/Stanfors 2011; Lundström/Andersson 2012). Unemployed women in Sweden are less likely than employed women to have a first and second birth but more likely to progress from a second to a third birth (Andersson et al. 2017). Regarding students, it has been shown that they are especially unlikely to have positive fertility intentions (e.g. Hiekel/Castro-Martín 2014) and to enter parenthood (Scott/Stanfors 2011; Ni Bhrolchaín/Beaujouan 2012).

\section{Hypotheses}

Based on the review of theory and earlier research on fertility behaviour among immigrants and immigrant descendants and on fertility intentions and other types of fertility preferences more generally, the following may be expected regarding intergenerational patterns in fertility intentions among immigrants and immigrant descendants in Sweden.

General intergenerational patterns in the fertility intentions of immigrants and their children:

Given the competing processes of socialisation into the culture of the origin country and adaptation to the context of the destination country, the following can be expected: 
H1a: Among immigrants and children of immigrants, individuals who have spent more of their formative years in the origin country and less in the destination country are more likely to be socialised into patterns that differ from those of non-immigrants in the destination country. Thus, differences compared to Swedes without an immigrant background should be greatest for the first generation, smaller for the 1.5 generation, and smallest for the second generation.

$\mathrm{H} 1 \mathrm{~b}$ : Since socialisation into a minority culture in the destination country is more likely for the second generation with two foreign-born parents than for the second generation with one foreign-born parent, the latter should differ less from non-immigrants.

Gender differences in the fertility intentions of immigrants and their children:

Based on Goldscheider's and Uhlenberg's (1969) minority group status hypothesis and the gender gap in educational performance among the second generation (see section 2.1 for further discussion), the following may be expected:

$\mathrm{H} 2$ : Intergenerational patterns should differ by gender, with female children of immigrants being less likely than male children of immigrants to state a positive fertility intention.

Origin group differences in the fertility intentions of immigrants and their children: Given earlier findings on differences across origin groups in actual fertility, the following can be expected for fertility intentions:

H3a: Immigrants and immigrant descendants with an origin in Western countries should be similar to non-immigrants both in the first and subsequent generations.

H3b: Immigrants and immigrant descendants of Eastern European origin should be less likely than non-immigrants to state a positive intention in both the first and subsequent generations.

H3c: Immigrants and immigrant descendants of Middle Eastern/North African or "other non-European" origin should be more likely than non-immigrants to state a positive intention in the first generation and display less than full convergence in subsequent generations.

\section{Research design}

\subsection{Data and sample selection}

This study uses data from Wave 1 of the Swedish Generations and Gender Survey (GGS) from 2012/2013. With a 53.8 percent response rate, the number of respondents in the Swedish GGS is 9,688, including both men and women aged between 18 and 79 years. Information was collected by Statistics Sweden via telephone interviews, register data, and a follow-up postal/online questionnaire (Thomson et al. 2015). 
The sample used in this study ${ }^{3}$ consists of 3,932 individuals. Out of the 4,060 respondents in the initial sample who were asked about their short-term fertility intentions, 128 respondents were excluded either because they were not able to choose between the four available substantive response alternatives $(n=92)$, had unclear migration histories or for other reasons did not easily fit into the categories of the main explanatory variables $(n=11)$, or because they had a same-sex partner $(n=25)$. The reason for excluding the latter group is that it is too small to be analysed separately, which would be preferable given its specific barriers to realisation of fertility intentions. Individuals for whom, or for whose partner, it was not physically possible to have (more) children and those who, or whose partner, were pregnant at the time of interview were not asked about their intentions and are therefore not included. Individuals who intend to adopt are not included since the Swedish GGS does not allow this to be separated from the intention to take a foster child, which is not easily comparable to the intention to have a biological or adopted child.

\subsection{Variables}

The dependent variable of all three analytical steps of this study is the intention to have a/another child within the next three years. The possible categories are definitely no, probably no, probably yes, and definitely yes. Further description of the dependent variable was provided in the previous section. See Appendix Table 1 for the sample distribution across categories for this and all other variables.

The first main explanatory variable is immigrant generation status, which has five categories: non-immigrants (primarily Swedish-born individuals with two Swedishborn parents, but also some foreign-born individuals who have two Swedish-born parents and moved to Sweden prior to age 15, thus including adoptees), first generation (foreign-born individuals without Swedish-born parents who immigrated at age 15 or later), 1.5 generation (foreign-born individuals without Swedish-born parents who immigrated prior to age 15), second generation (i.e. Swedish-born individuals) with two foreign-born parents, and second generation with one foreignborn parent (primarily Swedish-born individuals, but also foreign-born individuals who moved to Sweden prior to age 15).

Gender is the second main explanatory variable. In the Swedish GGS, women were asked about their short-term fertility intention if they were 18-45 years old at the time of interview, while men were asked about their intention if they were either single or had a female partner who was $18-45$ years old. The lack of an upper age limit for men means that their age range is considerably wider than that of women. Nonetheless, all but 19 men in the final sample are 55 years old or younger.

The third main explanatory variable is origin, which has five categories: non-immigrants (see description above), Western countries (including Western, Northern, and Southern Europe, as well as the United States, Canada, Australia, and New Zealand; the most common national origins in the final sample are Finland, Germany,

3 Hereafter referred to as "the final sample" 
Norway, and Denmark), Eastern European countries (including most of the former state socialist countries in Central and South Eastern Europe and the Caucasus, as well as Russia and the former Soviet Union, excluding post-Soviet Central Asia; the most common national origins are the former Yugoslavia, Poland, Bosnia and Herzegovina, and Estonia), Middle Eastern/North African countries (MENA) (including Turkey, Afghanistan, and Pakistan, but not Sudan, post-Soviet Central Asia, and the Caucasus; the most common national origins are Iraq, Iran, Turkey, and Syria), and other non-European countries (where the most common national origins are Chile, Somalia, Thailand, and The Gambia). The origin of the second generation with one Swedish-born and one foreign-born parent is categorised according to the origin of the foreign-born parent. Individuals with two foreign-born parents with different origins are categorised according to the origin of the mother. ${ }^{4}$

The control variables included in the further analysis are those discussed in section 2.3, i.e. age (continuous), educational attainment (university education/no university education), labour market status (full-time employed, part-time employed, unemployed, student, or other employment status ${ }^{5}$ ), partnership status (married, cohabiting, in a non-cohabiting union, singles), parity (childless, one child, two or more children), and number of siblings (continuous: $0-" 4$ or more"), plus age squared and gender (only included in the aggregate-level analysis and the analysis of origin differences). ${ }^{6}$

\subsection{Method and modelling strategy}

This study uses binary logistic regression to analyse how the propensity to state a positive vs. negative short-term fertility intention (i.e. probably + definitely yes vs. probably + definitely no) differs across groups. While the distinction between positive and negative intentions can be seen as most interesting, the degree of certainty (i.e. probably or definitely yes/no) also contains meaningful information (see Morgan 1982; Thomson/Brandreth 1995). For example, it has been found that uncertain and certain respondents differ considerably in their realisation of intentions (e.g. Toulemon/Testa 2005) and that uncertainty levels vary within the population according to factors such as age and labour market status (Berrington/Pattaro 2014). In order to incorporate the degree-of-certainty dimension into the analyses of this study, the binary yes/no approach is complemented with the partial proportional odds model, which is a variant of the ordered logit model (see O'Connel/ 2006;

4 The opposite approach, i.e. to categorise according to the origin of the father, would result in only 15 individuals switching category.

5 The "other employment status" category is made up of the relatively uncommon employment statuses parental leave, retired, homemaker, and other.

6

Twelve individuals in the final sample have missing or unclear information for one of the control variables, see Appendix Table 1 for information on which variables this concerns. These individuals are maintained in the sample and assigned to a specific missing category (which is not presented or discussed in the results section) for categorical variables (eleven cases) and to the mean for continuous variables (one case). 
Williams 2006, 2016). The basic idea of the two models is similar, i.e. to conduct a series of binary logistic regressions by cumulatively combining the categories of the ordinal dependent variable (here: categories 1 vs. $2-4,1-2$ vs. 3-4, and 1-3 vs. 4). However, while the ordered logit model assumes that odds are proportional across all the binary regressions for all independent variables and summarizes the series of regressions into only one set of results, the partial proportional odds model allows the odds to vary for variables that violate the assumption of proportional odds at a given significance level (in this study: 5 percent). ${ }^{7}$

The analytical strategy is as follows. First, intentions are compared across categories of immigrant generation status to study whether there is a trend of intergenerational convergence towards non-immigrant patterns at the aggregate level. Second, a similar analysis is performed separately for men and women in order to study whether intergenerational patterns differ by gender. Third, a 17-category variable that combines generational status and origin (non-immigrants +4 immigrant generational categories $\times 4$ immigrant origin categories) is used to study whether intergenerational patterns differ across origin groups. Each of these three analytical steps uses two different binary logistic regression models, while sample size limitations mean that the partial proportional odds model is used only for the first two steps. The first binary model controls for demographic variables that have a clear and strong connection to the formation of fertility intentions: age at interview, age at interview squared, gender (only for the aggregate-level analysis and the analysis of origin differences), parity, and partnership status. In addition to the variables of the first model, the second binary model also controls for socioeconomic status, i.e. educational attainment and employment status, as well as for the number of siblings. The partial proportional odds models include all the demographic and socioeconomic control variables.

\section{$5 \quad$ Results}

\subsection{Intergenerational patterns at an aggregate level}

The analysis of intergenerational patterns in the short-term fertility intentions of immigrants and immigrant descendants in Sweden is conducted in three steps: at the aggregate level, by gender, and across origins. Starting at the aggregate level, results indicate that a process of intergenerational convergence is indeed taking place (see Table 1). While the first generation, 1.5 generation, and second generation with two foreign-born parents are all significantly more likely than non-immigrants to state a positive intention, odds ratios are highest for the first generation. The differ-

7 An alternative to the partial proportional odds model would have been linear regression (see Billings/ey/Ferrarini 2014). It is not clear, however, to what extent the continuous approximation of the four-category intention variable is appropriate (see Thomson/Brandreth 1995). Linear regressions were conducted as a robustness check for the partial proportional odds models, with the results being mostly similar. These results are not shown but are available upon request. 


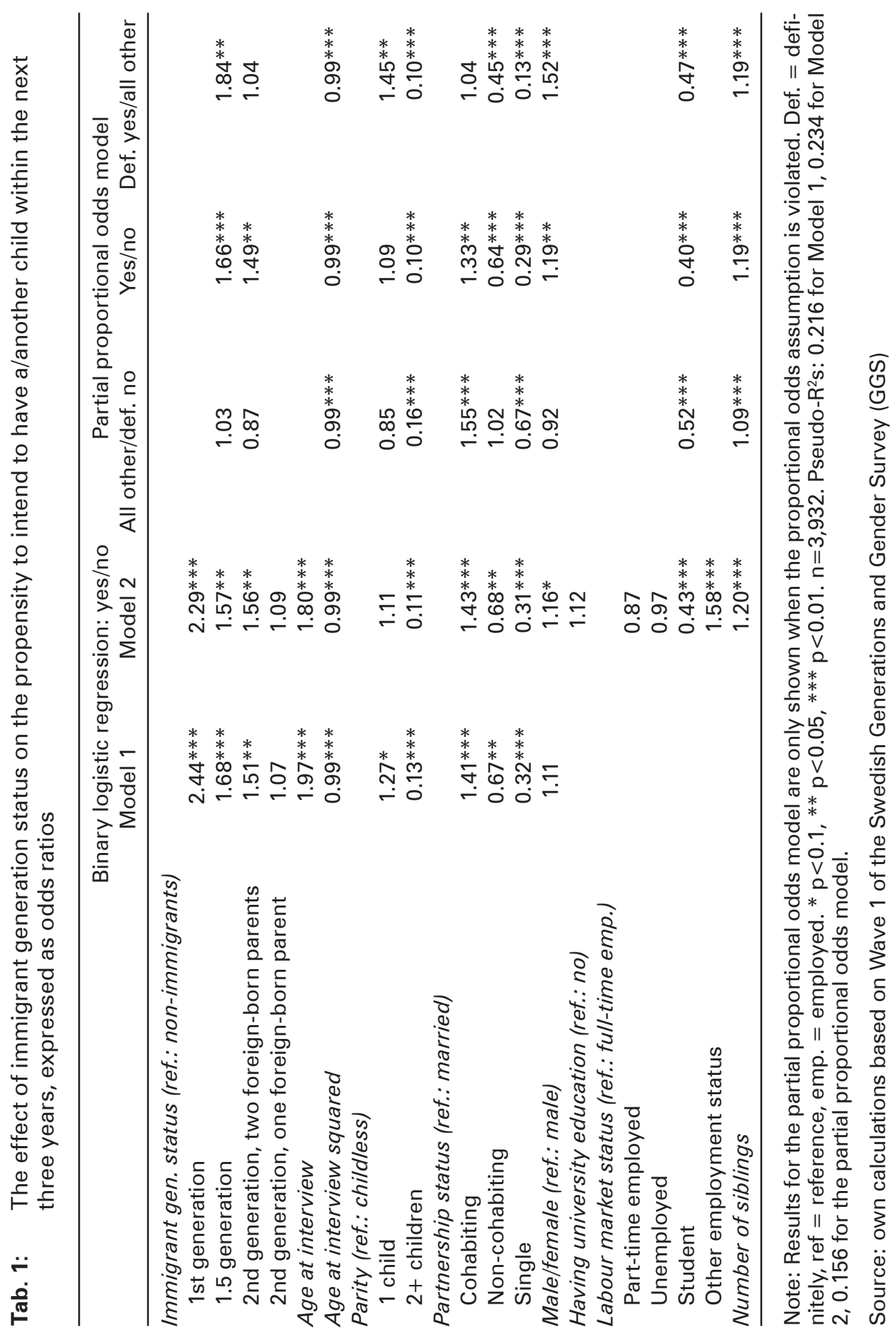


ence between the first generation and the second generation with two foreign-born parents is significant in both the binary model without socioeconomic controls and in the partial proportional odds model. The 1.5 generation and second generation with two foreign-born parents are similarly likely to state a positive intention, but results from the partial proportional odds model show that only the former group is more likely than non-immigrants to state a "definitely yes" intention. It is possible to interpret this greater uncertainty among the second generation with two foreignborn parents as a further step towards convergence compared to the 1.5 generation. Thus, comparing the first generation to subsequent generations provides support for hypothesis 1a, which stated that generations that are socialised to a greater extent in the destination country should be more similar to non-immigrants compared to generations that are socialised to a greater extent in the origin country. However, it should be stressed that the convergence process is not completed, as the second generation with two foreign-born parents is still more likely than non-immigrants to state a positive intention. In line with hypothesis $1 \mathrm{~b}$, the second generation with one foreign-born parent is more similar to non-immigrants than the second generation with two foreign-born parents is. It seems that the group differences described here cannot be attributed to socioeconomic characteristics, since adding educational attainment and labour market status to the analysis has only minor effects on the results.

In order to test whether the greater propensity of the first generation to state a positive intention can be attributed to extra high fertility in the period following shortly after migration, as stated by the interrelation-of-events hypothesis on immigrant fertility, additional models excluding individuals who immigrated to Sweden less than five years before the GGS interview were estimated. As these results are very similar to those presented in Table 1, the interrelation of demographic events in relation to migration does not seem to be a key factor in explaining the greater propensity of the first generation to state a positive fertility intention.

\subsection{Intergenerational patterns by gender}

For the second step of the analysis, i.e. whether intergenerational patterns differ by gender, an analytical procedure similar to that applied to the full final sample is performed separately for male and female subsamples. Results indicate that while both men and women of the first generation are significantly more likely than nonimmigrants of the same gender to state a positive fertility intention, there are considerable gender differences in subsequent generations (see Table 2). For women, convergence to non-immigrant patterns seems to take place relatively quickly, as no other generational category is significantly different from non-immigrant women. For men, on the other hand, both the 1.5 generation and the second generation with two foreign-born parents are more likely than non-immigrant men to state a positive fertility intention, with neither of these two children-of-immigrant groups being significantly different from the first generation (although the first/1.5 generation difference comes close to significance in Model 1). Even men of the second generation with one foreign-born parent are significantly more likely than non-immigrant men 


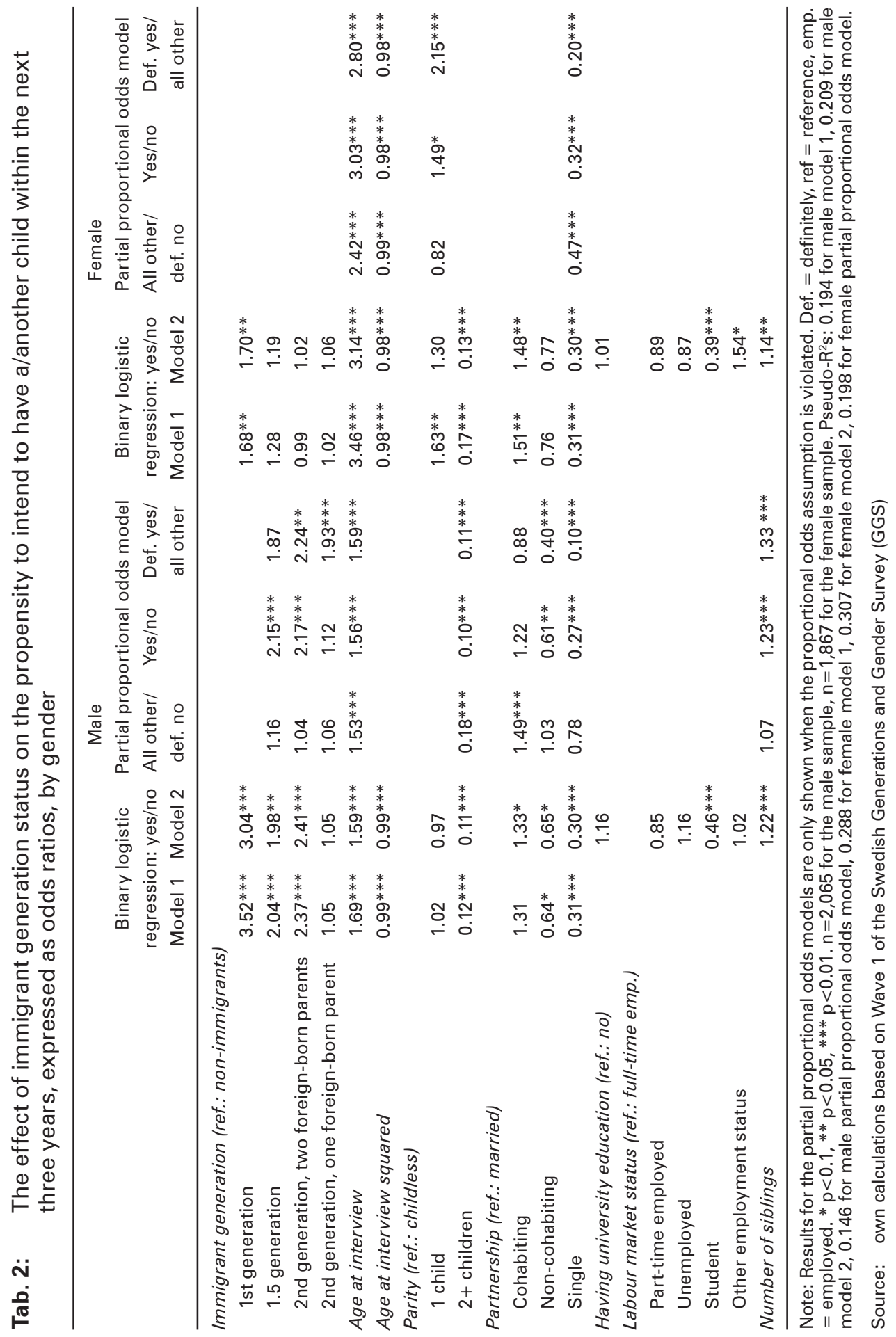


to state a "definitely yes" intention. These findings are in line with hypothesis 2 , which stated that female children of immigrants should be less likely to state a positive intention than male children of immigrants. Again, it does not seem that group differences can be explained by socioeconomic characteristics, since there are only minor changes to the results from adding educational attainment and labour market status to the analysis.

In order to test whether there are gender differences within the generational groups, binary logistic regressions were performed separately for each generational category, using the control variables of Model 1. Results from these models (which are not shown, but are available upon request) show that non-immigrant men are significantly less likely than non-immigrant women to state a positive fertility intention, while men of the first generation and the second generation with two foreign-born parents are significantly more likely than women of the same generational category to state a positive intention. Within the 1.5 generation and the second generation with one foreign-born parent, the fertility intentions of men and women do not significantly differ from each other. Thus, the gender differences within these two groups that appear in Table 2 are attributable primarily to gender differences within the non-immigrant reference group. The gender differences that are found within some origin groups are not attributable to differences in the age distribution between men and women in the final sample, since excluding men who are above 45 years of age does not change the results.

\subsection{Intergenerational patterns across regional origin groups}

The third step of the analysis is to test whether intergenerational patterns differ by origin. Since this analysis uses the same sample and mostly the same variables as the aggregate-level analysis, the results for the control variables are very similar to those already presented in Table 1 and are therefore neither shown nor discussed.

Results show that there are considerable differences between the origin groups (see Table 3). In line with hypothesis 3a, the Western origin group is similar to nonimmigrants in every generational category. However, contrary to the expectations of hypothesis 3b, no generational category of the Eastern European origin group is less likely than non-immigrants to state a positive intention. Instead, both the first and the 1.5 generation of Eastern European origin are more likely than non-immigrants to state a positive intention, while both second-generation groups are similar to non-immigrants. Thus, there is support for a trend of intergenerational convergence towards non-immigrant patterns for the Eastern European origin group. The intergenerational convergence trend is also observed for the "other non-European" origin group, which is more likely than non-immigrants to state a positive fertility intention in the first generation but not in any other generational category. According to hypothesis 3c, both the "other non-European" and the Middle Eastern/North African origin group should be more likely than non-immigrants to state a positive intention in the first generation and display less than full convergence among children-of-immigrant generations. While the former group does not follow this pattern, results for the latter are in line with expectations: Individuals of MENA origin are 
Tab. 3: The effect of immigrant generation status and origin on the propensity to intend to have a/another child within the next three years, expressed as odds ratios

Binary logistic regression: yes/no Model 1 Model 2

\begin{tabular}{lll}
\hline Immigrant origin and generation (ref: non-immigrants) & & \\
Western origin & & \\
1st generation & 1.52 & 1.58 \\
1.5 generation & 0.79 & 0.85 \\
2nd generation, two foreign-born parents & 1.26 & 1.24 \\
2nd generation, one foreign-born parent & 1.15 & 1.18 \\
Eastern European origin & $2.11^{* * *}$ & $2.24^{* * *}$ \\
1st generation & $2.07^{* *}$ & $1.91^{*}$ \\
1.5 generation & 1.18 & 1.40 \\
2nd generation, two foreign-born parents & 0.58 & 0.57 \\
2nd generation, one foreign-born parent & & \\
Middle Eastern/North African origin & $3.37^{* * *}$ & $2.80^{* * *}$ \\
1st generation & $2.09^{* *}$ & $1.88^{*}$ \\
1.5 generation & $2.89^{* *}$ & $2.78^{* *}$ \\
2nd generation, two foreign-born parents & 1.13 & 1.08 \\
2nd generation, one foreign-born parent & & \\
Other non-European origin & $2.82^{* * *}$ & $2.52^{* * *}$ \\
1st generation & 1.26 & 1.24 \\
1.5 generation & 1.46 & 1.58 \\
2nd generation, two foreign-born parents & 1.22 & 1.20 \\
2nd generation, one foreign-born parent & \\
\hline
\end{tabular}

Note: Results for the control variables are omitted since they are not of primary interest and since they are very similar to those already presented in Table 1. In Model 1, the control variables are age at interview, age at interview squared, parity, partnership status, and gender. Model 2 also includes educational attainment, labour market status, and number of siblings. ${ }^{*} p<0.1,{ }^{*} p<0.05,{ }^{* *} p<0.01$. $n=3,932$. Pseudo- ${ }^{2}$ s: 0.219 for Model 1, 0.236 for Model 2.

Source: own calculations based on Wave 1 of the Swedish Generations and Gender Survey (GGS)

more likely than non-immigrants to state a positive intention in every generation, except the second generation with one foreign-born parent.

\subsection{Effects of the control variables on fertility intentions}

A few comments can be made regarding the results for how the different control variables affect the propensity to state a positive fertility intention. Patterns for the demographic variables are largely in line with what could be expected given earlier findings (see section 2.3). It can be noted that cohabiting individuals are more likely than married individuals to state a positive intention, but not a definitely positive intention, indicating that uncertainty affects the former more than the latter. The positive effect of age is much more pronounced for women than for men. A positive association between being at parity one and stating a positive intention is found only 
for women, and it seems that it is the propensity to state a "definitely yes" intention that contributes most to this gender difference. Regarding the socioeconomic variables, educational attainment does not have a significant effect on fertility intentions. Perhaps surprisingly, neither being employed part-time nor being unemployed is associated with a lower propensity to state a positive intention relative to being employed full-time. The gender difference in the effect of "other employment status" is likely due to the fact that the proportion of parental-leave takers within this category is much greater among women than among men.

\section{Discussion and conclusions}

This study examines short-term, parity-progression fertility intentions of first-generation immigrants and their children in Sweden. Using data from Wave 1 of the Swedish Generations and Gender Survey from 2012/2013, the study analyses the extent to which intentions tend to converge towards non-immigrant patterns over immigrant generations. Intergenerational trends in fertility intentions are analysed at the aggregate level, by gender and across origin groups. The rationale for approaching immigrant fertility from this perspective is that fertility preferences provide information about the degree of adaptation to the fertility patterns of the destination country at an ideational level. Compared to only examining actual childbearing, this contributes an additional dimension to the understanding of immigrant fertility.

The study shows that the process of convergence towards non-immigrant patterns over immigrant generations which has been observed in the literature on actual fertility is often also reflected in intentions. Thus, it seems that behavioural adaptation does not only consist of adaptation to the institutional context of the destination country, but that there also is adaptation at an ideational level. At the aggregate level, the intentions of the 1.5 generation and the second generation with two foreign-born parents are less positive than those of the first generation, but more positive than those of non-immigrants, indicating that convergence is taking place but is incomplete. The second generation with one foreign-born parent is similar to non-immigrants, which holds both at aggregate level and at almost all other stages of the analysis. However, for the other generational groups, the aggregate-level patterns hide considerable differences both by gender and across origin groups. There is no clear intergenerational trend for male immigrants and children of immigrants, whose intentions are more positive than those of non-immigrants in both the first and subsequent generations. Women, on the other hand, have more positive intentions in the first generation and then converge to non-immigrant patterns by the 1.5 generation. Among origin groups, a convergence trend is evident only for the Eastern European and "other non-European" groups, who start out with more positive intentions in the first generation but are similar to non-immigrants by the second generation with two foreign-born parents and the 1.5 generation respectively. The Western origin group is similar to non-immigrants from the outset in the first generation, thereby excluding the possibility of convergence. The Middle Eastern/North African (MENA) origin group has more positive intentions than non- 
immigrants in both the first and subsequent generations, with no clear intergenerational trend.

The absence of a clear intergenerational convergence trend for the fertility intentions of the MENA origin group is in line with earlier research on actual fertility among children of Middle Eastern immigrants in Sweden, which has shown that differences in relation to non-immigrants persist in the second generation (Scott/Stanfors 2011; Andersson et al. 2017). Since it can be argued that patterns found among immigrant descendants are, in general, indicative of the longer-term integration of immigrant groups into destination societies (see De Valk/Milewski 2011; Milewski 2011) and since childbearing preferences represent fundamental motivations for the life course, high-fertility intentions in the second generation may imply the emergence of a persistent demographic subculture. Whether further convergence will occur in the third generation of MENA origin in Sweden and in other similar groups elsewhere is therefore an interesting topic for future research.

However, it should be stressed that group differences in the propensity to state a positive fertility intention do not necessarily translate into corresponding differences in actual fertility. As earlier research has shown that a large set of factors influence the realisation of fertility preferences (e.g. Régnier-Loilier/Vignoli 2011; Kuhnt/Trappe 2016), it is plausible that differences based on ethnicity or national origin also exist. Indeed, the findings of this study indicate that group differences in realisation patterns may exist in Sweden, as the fertility intentions of the Eastern European origin group are not in line with earlier findings on its fertility behaviour. The greater propensity to state a positive intention relative to non-immigrants in the first and 1.5 generation and similarity to non-immigrants in the second generation contrast with findings of depressed actual fertility compared to non-immigrants in Sweden among both the first and second generation of Eastern European origin (Andersson 2004; Scott/Stanfors 2011). These indications of lower realisation among the Eastern European origin group than among other groups in Sweden are in line with findings that realisation is lower in Eastern than in Western Europe (Spéder/Kapitány 2014). Spéder and Kapitány (2014) suggest that low levels of realisation in Eastern Europe can be traced back to a "differential pace of structural and cultural change" since the end of state socialism. The argument is that dramatic changes to the economic system and to the design of welfare services have led to general uncertainty and a tendency to prioritise risk aversion among Eastern European populations while pro-family ideals have persisted, resulting in relatively high but often unrealised fertility preferences.

A similar mechanism could be relevant for understanding how the immigration experience may be related to realisation processes beyond the effect of group differences in demographic and socioeconomic composition. It is likely that nonimmigrants are on average better informed about the institutional limitations and possibilities of the destination country and therefore less likely than immigrants and children of immigrants to over-estimate their fertility intentions. Thus, group differences in realisation could arise if the impact of practical constraints on childbearing outcomes work more via the formation of fertility intentions for some groups and more at the level of realisation for others. It is even possible to imagine a social 
desirability bias towards providing positive answers to survey questions on fertility preferences among groups where there is greater value attached to high-fertility behaviour than is typically the case among non-immigrants in Sweden. Groups that are more affected by such a bias should have less realistic intentions and thus lower realisation compared to other groups. Analysing this type of hypotheses makes the study of how fertility intentions are realised among immigrants and their children an interesting topic for future research.

By studying whether fertility intentions vary by gender, this study contributes to an often-overlooked perspective in research on the fertility of immigrants and immigrant descendants (see Ortensi 2015). Findings that convergence is much more evident among women than among men are in line with the expectations of hypothesis 2 . However, the sample size used in this study did not allow for a full analysis of the proposed explanation for the gender gap, i.e. that gender differences in educational performance among children of immigrants may also produce differences in fertility intentions. Further exploring the merits of this hypothesis is an interesting topic for future scholarship. It should be noted that the gender gap in convergence is partly attributable to gender differences among the non-immigrant reference group, among whom women are more likely than men to state a positive intention. As earlier studies have not found that women have considerably more positive fertility preferences than men (Berrington 2004; Miettinen/Paajanen 2005; Hartnett 2014; Dommermuth et al. 2015), this pattern could be specific to the Swedish nonimmigrant population, which should be considered when generalising these findings to contexts outside Sweden. Another interesting perspective for future work relating to the gender gap in fertility intentions among immigrants and immigrant descendants is the process of reconciliation between male and female partners in both ethnically homogamous and heterogamous unions. In some contexts, it might prove useful to study fertility decision-making among immigrants and their children beyond the level of the individual, since it is possible that men's preferences and the preferences of the extended family weigh heavier among some immigrant communities than they typically do in the relatively gender-egalitarian and individualistic Swedish majority culture.

This study demonstrates the usefulness of not only studying whether a fertility intention is positive or negative, but also of including the degree-of-certainty dimension in the analysis. For some of the variables, most notably parity and partnership status, the partial proportional odds models display interesting patterns that were not detected by the binary models. This study also demonstrates that it is meaningful to distinguish among the second generation between those with two foreign-born parents and those with one foreign-born parent, with the latter often being more similar to non-immigrants. Studies that group the two second generation groups together are likely to find more similarities between non-immigrants and the second generation than would otherwise be the case. Similarly, the results indicate that it is also meaningful to distinguish among foreign-born individuals between those who migrated as adults and those who migrated as children (referred to in this study as the first and 1.5 generations), since individuals who migrated as children are sometimes closer to those who migrated as adults and sometimes 
to the second generation with two foreign-born parents. While this study focused on intentions, future research should investigate whether similar patterns also apply to other types of fertility preferences. The desired number of children represent an earlier stage in the formation of fertility preferences that is less affected by perceived external constraints, and thereby provide a different type of information about individuals' demographic value orientation.

There are, however, some important limitations to this study, which should be considered in future research. The relatively small sample size in some instances reduced the possibilities of attaining statistically significant results, primarily for the analysis of generational differences among regional origin groups. Future research could benefit from using data sources with larger samples of immigrants and immigrant descendants. Larger samples could also allow for analyses of more disaggregated categorisations of origin. The aggregation from national into regional origins is likely to hide many interesting patterns, as low- and high-fertility subgroups probably even each other out. For example, Andersson (2004) finds that there are important differences among Middle Eastern immigrant groups in Sweden, as Iranians tend to have lower fertility than non-immigrants while individuals with an origin in Arab countries tend to have higher fertility. It is important to consider the composition of the broad origin groups analysed in this study when aiming to generalise the findings of this study to contexts outside Sweden. Also, it should be noted that shifts in immigration flows over time mean that the national origin composition of the regional origin groups differs to some extent across generational categories, which may affect the possibilities to interpret generational differences as intergenerational change.

In addition to national origin, future research could benefit from studying the effect of sub- or transnational identities, such as ethnicity, on the formation of fertility preferences. It is reasonable to assume the impact of culture (e.g. in the form of socialisation or reactive ethnicity) to often work at the level of ethnicity rather than nationality. Looking exclusively at country of birth is likely to be an especially insufficient approach for analysing Sweden's immigrants of Middle Eastern origin, since two transnational ethnic minorities in the region of origin, i.e. Kurds and Assyrians/ Syriacs, constitute important segments of this group. As Kurds in Turkey have been found to have higher rates of higher-order births than non-Kurds (Yavuz 2006), differences are also possible after arrival in the destination country. When information about ethnicity is not available, a possible alternative in some cases could be to use data on language as a proxy.

It would also have been interesting to include religious denomination, religiosity, and conservative/liberal attitudes as control variables, given earlier findings on their association with both fertility preferences and actual fertility (e.g. Westoff) Frejka 2007; Philipov/Berghammer 2007; Kulu/Hannemann 2016). Such factors could be important explanations for the observed group differences in the propensity to state a positive fertility intention. However, including these types of variables was not possible since the relevant items in the Swedish GGS were part of the follow-up postal/online questionnaire which was only filled out by slightly more than half of the respondents in the final sample. 
Finally, the topic of this study is situated within a wider debate on immigrant integration and ethnic relations that constitutes one of the most important conflict dimensions in contemporary Swedish society (Demker 2015). As immigrant fertility is an important element of this debate, there is a considerable degree of political salience to the findings. Variation across groups in the pace and extent of convergence can be considered controversial since they signal both the persistence of subcultures and possible future shifts in the demographic composition of society. However, since childbearing preferences constitute fundamental motivations for the life course, a general trajectory towards ideational assimilation in this area is encouraging for the prospects of broader integration among immigrants in Sweden.

\section{Acknowledgements}

I am especially grateful to Eleonora Mussino for her invaluable support throughout the process leading up to this article. Nadja Milewski, Gunnar Andersson, Livia Sz. Oláh, Chiara Comolli, Gerda Neyer, two anonymous reviewers, and the editorial board at $\mathrm{CPOS}$ also provided very useful suggestions that contributed to improving the paper. The research received financial support from the Swedish Research Council through the Swedish Initiative for Research on Microdata in the Social and Medical Sciences (SIMSAM): Stockholm University SIMSAM Node for Demographic Research, grant no. 340-2013-5164.

\section{References}

Ajzen, Icek; Klobas, Jane 2013: Fertility intentions. An approach based on the theory of planned behavior. In: Demographic Research 29,8: 203-232 [doi: 10.4054/DemRes.2013.29.8].

Andersson, Gunnar 2004: Childbearing after migration. Fertility patterns of foreignborn women in Sweden. In: International Migration Review 38,2: 747-774 [doi: 10.1111/ j.1747-7379.2004.tb00216.x].

Andersson, Gunnar; Obućina, Ognjen; Scott, Kirk 2015: Marriage and divorce of immigrants and descendants of immigrants in Sweden. In: Demographic Research 33,2: 31-64 [doi: 10.4054/DemRes.2015.33.2].

Andersson, Gunnar; Persson, Lotta; Obućina, Ognjen 2017: Depressed fertility among descendants of immigrants in Sweden. In: Demographic Research 36,39: 1149-1184 [doi: 10.4054/DemRes.2017.36.39].

Andersson, Gunnar; Scott, Kirk 2005: Labour-market status and first-time parenthood. The experience of immigrant women in Sweden, 1981-97. In: Population Studies 59,1: 21-38 [doi: 10.1080/0032472052000332683].

Andersson, Gunnar; Scott, Kirk 2007: Childbearing dynamics of couples in a universalistic welfare state. The role of labor-market status, country of origin, and gender. In: Demographic Research 17,30: 897-938 [doi: 10.4054/DemRes.2007.17.30].

Bagavos, Christos; Tsimbos, Cleon; Verropoulou, Georgia 2008: Native and migrant fertility patterns in Greece: A cohort approach. In: European Journal of Population 24,3: 245-263 [doi: 10.1007/s10680-007-9142-6]. 
Balbo, Nicoletta; Billari, Francesco C.; Mills, Melinda 2013: Fertility in advanced societies: A review of research. In: European Journal of Population 29,1: 1-38 [doi: 10.1007/ s10680-012-9277-y].

Balbo, Nicoletta; Mills, Melinda 2011: The influence of the family network on the realisation of fertility intentions. In: Vienna Yearbook of Population Research 9: 179-206 [doi: 10.1553/populationyearbook2011s179].

Baykara-Krumme, Helen; Milewski, Nadja 2017: Fertility patterns among Turkish women in Turkey and abroad. The effects of international mobility, migrant generation, and family background. In: European Journal of Population 33,3: 409-436 [doi: 10.1007/ s10680-017-9413-9].

Berrington, Ann 2004: Perpetual postponers? Women's, men's and couples' fertility intentions and subsequent fertility behavior. In: Population Trends 117: 9-19.

Berrington, Ann; Pattaro, Serena 2014: Educational differences in fertility desires, intentions and behaviour: A life course perspective. In: Advances in Life Course Research 21: 10-27 [doi: 10.1016/j.alcr.2013.12.003].

Billari, Francesco C.; Philipov, Dimiter; Testa, Maria R. 2009: Attitudes, norms, and perceived behavioural control: Explaining fertility intentions in Bulgaria. In: European Journal of Population 25,4: 439-465 [doi: 10.1007/s10680-009-9187-9].

Billingsley, Sunnee; Ferrarini, Tommy 2014: Family policy and fertility intentions in 21 European countries. In: Journal of Marriage and Family 76,2: 428-445 [doi: 10.1111/ jomf.12097].

Bongaarts, John 2001: Fertility and reproductive practices in post-transitional societies. In: Population and Development Review 27: 260-281.

Brinton, Mary C. et al. 2018: Postindustrial fertility ideals, intentions, and gender inequality: A comparative qualitative analysis. In: Population and Development Review 44,2: 281-309 [doi: 10.1111/padr.12128].

Cavalli, Laura; Klobas, Jane 2013: How expected life and partner satisfaction affect women's fertility outcomes. The role of uncertainty in intentions. In: Population Review 52,2: 70-86.

Coleman, David A.; Dubuc, Sylvie 2010: The fertility of ethnic minorities in the UK, 1960s-2006. In: Population Studies 64,1: 19-41 [doi: 10.1080/00324720903391201].

Courbage, Youssef 1992: Demographic transition among Muslims in Eastern Europe. In: Population: An English Selection 4: 161-186.

Cygan-Rehm, Kamila 2014: Immigrant fertility in Germany. The role of culture. In: Journal of Applied Social Science Studies 134,3: 305-340 [doi: 10.3790/schm.134.3.305].

De Valk, Helga A. G. 2013: Intergenerational discrepancies in fertility preferences among immigrant and Dutch families. In: The History of the Family 18,2: 209-225 [doi: 10.1080/1081602X.2013.826591].

De Valk, Helga A. G.; Milewski, Nadja 2011: Family life transitions among children of immigrants: An introduction. In: Advances in Life Course Research 16,4: 145-151 [doi: 10.1016/j.alcr.2011.10.001]

Demker, Marie 2015: Mobilisering kring migration förändrar det svenska partisystemet [Mobilization around migration is changing the Swedish party system]. In: Bergström, Annika et al. (Eds.): Fragment. University of Gothenburg: SOM Institute: 261-271.

Dommermuth, Lars; Klobas, Jane; Lappegård, Trude 2011: Now or later? The Theory of Planned Behavior and timing of fertility intentions. In: Advances in Life Course Research 16,1: 42-53 [doi: 10.1016/j.alcr.2011.01.002]. 
Dommermuth, Lars; Klobas, Jane; Lappegård, Trude 2015: Realization of fertility intentions by different time frames. In: Advances in Life Course Research 24: 34-46 [doi: 10.1016/j.alcr.2015.02.001].

Eschelbach, Martina 2015: Family culture and fertility outcomes - Evidence from American siblings. In: Jahrbücher für Nationalökonomie und Statistik 235,3: 246-267 [doi: 10.1515/jbnst-2015-0302].

Fleischmann, Fenella et al. 2014: Gender inequalities in the education of the second generation in Western countries. In: Sociology of Education 87,3: 143-170 [doi: 10.1177/0038040714537836].

Garssen, Joop; Nicolaas, Han 2008: Fertility of Turkish and Moroccan women in the Netherlands: Adjustment to native level within one generation. In: Demographic Research 19,33: 1249-1280 [doi: 10.4054/DemRes.2008.19.33].

Goldscheider, Calvin; Uhlenberg, Peter R. 1969: Minority group status and fertility. In: American Journal of Sociology 74,4: 361-372.

Goldstein, Joshua; Lutz, Wolfgang; Testa, Maria Rita 2003: The emergence of sub-replacement family size ideals in Europe. In: Population Research and Policy Review 22,5/6: 479-496 [doi: 10.1023/B:POPU.0000020962.80895.4a].

Guarin Rojas, Eder Andres; Bernardi, Laura; Schmid, Flurina 2018: First and second births among immigrants and their descendants in Switzerland. In: Demographic Research 38,11: 247-286 [doi: 10.4054/DemRes.2018.38.11].

Hampshire, Kate; Blell, Mwenza; Simpson, Bob 2012: Navigating new socio-demographic landscapes: Using anthropological demography to understand the 'persistence' of high and early fertility among British Pakistanis. In: European Journal of Population 28,1: 39-63 [doi: 10.1007/s10680-011-9252-z].

Hartnett, Caroline Sten 2014: White-Hispanic differences in meeting lifetime fertility intentions in the U.S. In: Demographic Research 30,43: 1245-1276 [doi: 10.4054/DemRes.2014.30.43].

Heiland, Frank; Prskawetz, Alexia; Sanderson, Warren C. 2008: Are individuals' desired family sizes stable? Evidence from West German panel data. In: European Journal of Population 24,2: 129-156 [doi: 10.1007/s10680-008-9162-x].

Hiekel, Nicole; Castro-Martín, Teresa 2014: Grasping the diversity of cohabitation. Fertility intentions among cohabiters across Europe. In: Journal of Marriage and Family 76,3: 489-505 [doi: 10.1111/jomf.12112].

Holland, Jennifer A.; De Valk, Helga A. G. 2013: Ideal ages for family formation among immigrants in Europe. In: Advances in Life Course Research 18,4: 257-269 [doi: 10.1016/j.alcr.2013.08.002].

Kolk, Martin 2013: Understanding transmission of fertility across multiple generations Socialization or socioeconomic? In: Research in Social Stratification and Mobility 35: 89-103 [doi: 10.1016/j.rssm.2013.09.006].

Krapf, Sandra; Wolf, Katharina 2015: Persisting differences or adaptation to German fertility patterns? First and second birth behavior of the 1.5 and second generation Turkish migrants in Germany. In: Kölner Zeitschrift für Soziologie und Sozialpsychologie 67(1 suppl.): 137-164 [doi: 10.1007/s11577-015-0331-8].

Kraus, Elisabeth K.; Castro-Martín, Teresa 2018: Does migrant background matter for adolescents' fertility preferences? The Latin American 1.5 generation in Spain. In: European Journal of Population 34,3: 277-312 [doi: 10.1007/s10680-017-9427-3]. 
Kuhnt, Anne-Kristin; Kreyenfeld, Michaela; Trappe, Heike 2017: Fertility ideals of women and men across the life course. In: Kreyenfeld, Michaela; Konietzka, Dirk (Eds.): Childlessness in Europe: Contexts, Causes, and Consequences. Dordrecht: Springer: 235251.

Kuhnt, Anne-Kristin; Trappe, Heike 2016: Channels of social influence on the realization of short-term fertility intentions in Germany. In: Advances in Life Course Research 27: 16-29 [doi: 10.1016/j.alcr.2015.10.002].

Kulu, Hill; González-Ferrer, Amparo 2014: Family dynamics among immigrants and their descendants in Europe: Current research and opportunities. In: European Journal of Population 30,4: 411-435 [doi: 10.1007/s10680-014-9322-0]

Kulu, Hill; Hannemann, Tina 2016: Why does fertility remain high among certain UK-born ethnic minority women? In: Demographic Research 35,49: 1441-1488 [doi: 10.4054/ DemRes.2016.35.49].

Kulu, Hill et al. 2017: Fertility by birth order among the descendants of immigrants in selected European countries. In: Population and Development Review 43,1: 31-60 [doi: 10.1111/padr.12037].

Liefbroer, Aart C. 2009: Changes in family size intentions across young adulthood: A lifecourse perspective. In: European Journal of Population 25,4: 363-386 [doi: 10.1007/ s10680-008-9173-7].

Lundström, Karin E.; Andersson, Gunnar 2012: Labor market status, migrant status, and first childbearing in Sweden. In: Demographic Research 27,25: 719-742 [doi: 10.4054/ DemRes.2012.27.25].

Mayer, Jochen; Riphahn, Regina T. 2000: Fertility assimilation of immigrants: Evidence from count data models. In: Journal of Population Economics 13,2: 241-261 [doi: $10.1007 / \mathrm{s} 001480050136]$.

McQuillan, Kevin 2004: When does religion influence fertility? In: Population and Development Review 30,1: 25-56 [doi: 10.1111/j.1728-4457.2004.00002.x].

Miettinen, Anneli; Paajanen, Pirjo 2005: Yes, no, maybe. Fertility intentions and reasons behind them among childless Finnish men and women. In: Finnish Yearbook of Population Research 41: 165-184.

Milewski, Nadja 2007: First child of immigrant workers and their descendants in West Germany. In: Demographic Research 17,29: 859-896 [doi: 10.4054/DemRes.2007.17.29].

Milewski, Nadja 2010: Immigrant fertility in West Germany: Is there a socialization effect in transitions to second and third births? In: European Journal of Population 26,3: 297323 [doi: 10.1007/s10680-010-9211-0].

Milewski, Nadja 2011: Transition to a first birth among Turkish second-generation migrants in Western Europe. In: Advances in Life Course Research 16,4: 178-189 [doi: 10.1016/j.alcr.2011.09.002].

Miller, Warren B.; Pasta, David J. 1995: Behavioral intentions: Which ones predict fertility behavior in married couples? In: Journal of Applied Psychology 25,6: 530-555 [doi: 10.1111/j.1559-1816.1995.tb01766.x].

Morgan, S. Philip 1982: Parity-specific fertility intentions and uncertainty: The United States, 1970 to 1976. In: Demography 19,3: 315-334 [doi: 10.2307/2060974].

Murphy, Michael; Knudsen, Lisbeth B. 2002: The intergenerational transmission of fertility in contemporary Denmark. The effects of number of siblings (full and half), birth order, and whether male or female. In: Population Studies 56,3: 235-248 [doi: 10.1080/00324720215937]. 
Mussino, Eleonora; Strozza, Salvatore 2012: Does citizenship still matter? Second birth risks of migrants from Albania, Morocco, and Romania in Italy. In: European Journal of Population 28,3: 269-302 [doi: 10.1007/s10680-012-9261-6].

Ní Bhrolcháin, Máire; Beaujouan, Éva 2012: Fertility postponement is largely due to rising educational enrolment. In: Population Studies 66,3: 311-327 [doi: 10.1080/00324728.2012.697569].

O'Connell, Ann A. 2006: Logistic Regression Models for Ordinal Response Variables. Series: Quantitative applications in the social sciences 07-146. Electronic version of printed book. [doi: 10.4135/9781412984812].

Oh/sson-Wijk, Sofi 2011: Sweden's marriage revival: An analysis of the new-millennium switch from long-term decline to increasing popularity. In: Population Studies 65,2: 183-200 [doi: 10.1080/00324728.2011.574724].

Okun, Barbara S. 2016: An investigation of the unexpectedly high fertility of secular, native-born Jews in Israel. In: Population Studies 70,2: 239-257 [doi: 10.1080/00324728.2016.1195913].

Okun, Barbara S. 2017: Religiosity and fertility. Jews in Israel. In: European Journal of Population 33,4: 475-507 [doi: 10.1007/s10680-016-9409-x].

Ortensi, Livia E. 2015: Engendering the fertility-migration nexus: The role of women's migratory patterns in the analysis of fertility after migration. In: Demographic Research 32,53: 1435-1468 [doi: 10.4054/DemRes.2015.32.53].

Pailhé, Ariane 2017: The convergence of second-generation immigrants' fertility patterns in France: The role of sociocultural distance between parents' and host country. In: Demographic Research 36,45: 1361-1398 [doi: 10.4054/DemRes.2017.36.45].

Persson, Lotta; Hoem, Jan, M. 2014: Immigrant fertility in Sweden, 2000-2011: A descriptive note. In: Demographic Research 30,30: 887-898 [doi: 10.4054/DemRes.2014.30.30]

Philipov, Dimiter; Berghammer, Caroline 2007: Religion and fertility ideals, intentions and behavior: a comparative study of European countries. In: Vienna Yearbook of Population Research 5: 271-305 [doi: 10.1553/populationyearbook2007s271].

Philipov, Dimiter; Spéder, Zsolt; Billari, Francesco, C. 2006: Soon, later, or ever? The impact of anomie and social capital on fertility intentions in Bulgaria (2002) and Hungary (2001). In: Population Studies 60,3: 289-308 [doi: 10.1080/00324720600896080].

Puur, Allan et al. 2017: Childbearing among first- and second-generation Russians in Estonia against the background of the sending and host countries. In: Demographic Research 36,41: 1209-1254 [doi: 10.4054/DemRes.2017.36.41].

Régnier-Loilier, Arnaud; Vignoli, Daniele 2011: Fertility intentions and obstacles to their realization in France and Italy. In: Population 66,2: 361-390 [doi: 10.3917/ pope.1102.0361].

Rumbaut, Rubén, G. 2008: Reaping what you sow: Immigration, youth, and reactive ethnicity. In: Applied Development Science 12,2: 108-111 [doi: 10.1080/10888690801997341]

Sahu, Biswamitra; Hutter, Inge 2012: 'Lived Islam' in India and Bangladesh: Negotiating religion to realize reproductive aspirations. In: Culture, Health \& Sexuality 14,5: 521535 [doi: 10.1080/13691058.2012.672652].

Schoen, Robert et al. 1999: Do fertility intentions affect fertility behavior? In: Journal of Marriage and the Family 61,3: 790-799 [doi: 10.2307/353578].

Scott, Kirk; Stanfors, Maria 2011: The transition to parenthood among the second generation. Evidence from Sweden, 1990-2005. In: Advances in Life Course Research 16,4 190-204 [doi: 10.1016/j.alcr.2011.09.003]. 
Sobotka, Tomáš 2008: The rising importance of migrants for childbearing in Europe. In: Demographic Research 19,9: 225-248 [doi: 10.4054/DemRes.2008.19.9].

Sobotka, Tomáš; Beaujouan, Éva 2014: Two is best? The persistence of a two-child family ideal in Europe. In: Population and Development Review 40,3: 391-419 [doi: 10.1111/j.1728-4457.2014.00691.x].

Spéder, Zsolt; Kapitány, Balázs 2014: Failure to realize fertility intentions: A key aspect of the post-communist fertility transition. In: Population Research and Policy Review 33: 393-418 [doi: 10.1007/s11113-013-9313-6].

Statistics Sweden 2010: Födda i Sverige - ändå olika? Betydelsen av föräldrarnas födelseland [Born in Sweden - but still different? The significance of parents' country of birth]. Demographic reports 2010: 2.

Statistics Sweden 2014: Utrikes föddas barnafödande - före och efter invandring [Childbearing among foreign born - before and after migration to Sweden]. Demographic reports 2014: 4.

Testa, Maria Rita 2014: On the positive correlation between education and fertility intentions in Europe: Individual- and country-level evidence. In: Advances in Life Course Research 21: 28-42 [doi: 10.1016/j.alcr.2014.01.005].

Thomson, Elizabeth 2015: Family Size Preferences. In: Wright, James D. (Ed.): International Encyclopedia of the Social and Behavioral Sciences, 2nd edition, Volume 8. Oxford: Elsevier Ltd: 805-808 [doi: 10.1016/B978-0-08-097086-8.31064-9].

Thomson, Elizabeth; Brandreth, Yvonne 1995: Measuring fertility demand. In: Demography 32,1: 81-96 [doi: 10.2307/2061898].

Thomson, Elizabeth et al. 2015: A Swedish Generations and Gender Survey. Questionnaires in English translation. Stockholm Research Reports in Demography 2015: 16.

Toulemon, Laurent; Testa, Maria Rita 2005: Fertility intentions and actual fertility. A complex relationship. In: Population \& Societies 415: 1-4.

Van Landschoot, Lisa; De Valk, Helga A. G.; Van Bavel, Jan 2017: Fertility among descendants of immigrants in Belgium: The role of the partner. In: Demographic Research 36,60: 1827-1858 [doi: 10.4054/DemRes.2017.36.60].

Varley, Emma 2012: Islamic logics, reproductive rationalities: Family planning in Northern Pakistan. In: Anthropology \& Medicine 19,2: 189-206 [doi: 10.1080/13648470.2012.675044].

Westoff, Charles F.; Frejka, Tomas 2007: Religiousness and fertility among European Muslims. In: Population and Development Review 33,4: 785-809 [doi: 10.1111/j.17284457.2007.00197.x].

Wiik, Kenneth A.; Bernhardt, Eva; Noack, Turid 2009: A study of commitment and relationship quality in Sweden and Norway. In: Journal of Marriage and the Family 71,3: 465-477 [doi: 10.1111/j.1741-3737.2009.00613.x].

Williams, Richard 2006: Generalized ordered logit/partial proportional odds models for ordinal dependent variables. In: The Stata Journal 6,1: 58-82.

Williams, Richard 2016: Understanding and interpreting generalized ordered logit models. In: The Journal of Mathematical Sociology 40,1: 7-20 [doi: 10.1080/0022250X.2015.1112384].

Yavuz, Sutay 2006: Completing the fertility transition: Third birth developments by language groups in Turkey. In: Demographic Research 15,15: 435-460 [doi: 10.4054/DemRes.2006.15.15]. 
240 - Erik Carlsson

Erik Carlsson ( $\varangle$ ). Stockholm University, Department of Sociology. Stockholm, Sweden. E-mail: erik.carlsson@sociology.su.se

URL: https://www.su.se/english/profiles/erca5075-1.219780 


\section{Appendix}

Tab. A1: Descriptive statistics for the final sample (\%), by immigrant generation

\begin{tabular}{|c|c|c|c|c|c|c|}
\hline & $\begin{array}{l}\text { 1st gene- } \\
\text { ration }\end{array}$ & $\begin{array}{l}1.5 \text { gene- } \\
\text { ration }\end{array}$ & $\begin{array}{l}2 \text { nd gene- } \\
\text { ration, } \\
2 \text { foreign- } \\
\text { born } \\
\text { parents }\end{array}$ & $\begin{array}{c}\text { 2nd gene- } \\
\text { ration, } \\
1 \text { foreign- } \\
\text { born } \\
\text { parent }\end{array}$ & $\begin{array}{l}\text { Non- } \\
\text { immi- } \\
\text { grants }\end{array}$ & Total \\
\hline \multicolumn{7}{|l|}{ Intention } \\
\hline Definitely no & 36.2 & 45.2 & 49.7 & 44.2 & 45.9 & 45.1 \\
\hline Probably no & 25.5 & 21.7 & 20.0 & 28.3 & 27.0 & 26.5 \\
\hline Probably yes & 17.0 & 17.8 & 20.0 & 13.2 & 15.6 & 15.7 \\
\hline Definitely yes & 21.4 & 15.3 & 10.3 & 14.3 & 11.5 & 12.7 \\
\hline \multicolumn{7}{|l|}{ Gender } \\
\hline Male & 51.3 & 51.6 & 46.5 & 52.7 & 53.0 & 52.5 \\
\hline Female & 48.7 & 48.4 & 53.5 & 47.3 & 47.0 & 47.5 \\
\hline \multicolumn{7}{|l|}{ Regional origin } \\
\hline Western & 19.8 & 15.3 & 38.7 & 69.5 & & 10.2 \\
\hline Eastern European & 27.7 & 30.6 & 26.5 & 13.5 & & 5.7 \\
\hline MENA & 29.9 & 31.8 & 21.3 & 6.6 & & 5.1 \\
\hline Other non-European & 22.6 & 22.3 & 13.5 & 10.4 & & 4.2 \\
\hline Sweden & & & & & 100.0 & 74.7 \\
\hline \multicolumn{7}{|l|}{ Age at interview } \\
\hline $18-24$ & 6.9 & 43.3 & 42.6 & 37.4 & 28.5 & 28.7 \\
\hline $25-34$ & 31.4 & 33.1 & 25.8 & 28.6 & 29.3 & 29.5 \\
\hline $35-44$ & 49.7 & 17.8 & 28.4 & 27.2 & 34.6 & 34.2 \\
\hline 45 or older & 11.9 & 5.7 & 3.2 & 6.9 & 7.6 & 7.6 \\
\hline \multicolumn{7}{|l|}{ Educational attainment } \\
\hline No university education & 57.2 & 69.4 & 72.3 & 69.0 & 67.3 & 66.9 \\
\hline University education & 42.5 & 30.6 & 27.7 & 31.0 & 32.7 & 33.1 \\
\hline Missing information & 0.3 & & & & 0.0 & 0.1 \\
\hline \multicolumn{7}{|l|}{ Labour market status } \\
\hline Full-time employed & 52.5 & 40.1 & 51.0 & 49.5 & 54.9 & 53.5 \\
\hline Part-time employed & 17.9 & 14.6 & 9.0 & 14.0 & 16.2 & 15.8 \\
\hline Unemployed & 9.1 & 6.4 & 6.5 & 5.8 & 5.0 & 5.5 \\
\hline Student & 10.4 & 29.3 & 31.0 & 25.3 & 17.6 & 18.7 \\
\hline Other employment status & 8.8 & 8.9 & 2.6 & 5.5 & 6.1 & 6.3 \\
\hline Missing information & 1.3 & 0.6 & & & 0.1 & 0.2 \\
\hline
\end{tabular}


Tab. A1: Continuation

\begin{tabular}{|c|c|c|c|c|c|c|}
\hline & $\begin{array}{l}\text { 1st gene- } \\
\text { ration }\end{array}$ & $\begin{array}{c}1.5 \text { gene- } \\
\text { ration }\end{array}$ & $\begin{array}{l}\text { 2nd gene- } \\
\text { ration, } \\
2 \text { foreign- } \\
\text { born } \\
\text { parents }\end{array}$ & $\begin{array}{l}2 \text { nd gene- } \\
\text { ration, } \\
1 \text { foreign- } \\
\text { born } \\
\text { parent }\end{array}$ & $\begin{array}{l}\text { Non- } \\
\text { immi- } \\
\text { grants }\end{array}$ & Total \\
\hline \multicolumn{7}{|l|}{ Parity } \\
\hline Childless & 27.0 & 65.0 & 59.4 & 61.5 & 53.1 & 52.5 \\
\hline 1 child & 17.9 & 8.9 & 13.5 & 11.0 & 11.6 & 12.1 \\
\hline 2 or more children & 55.0 & 26.1 & 27.1 & 27.5 & 35.3 & 35.5 \\
\hline \multicolumn{7}{|l|}{ Partnership status } \\
\hline Married & 54.4 & 22.9 & 24.5 & 21.4 & 26.9 & 28.3 \\
\hline Cohabiting & 18.6 & 14.6 & 16.1 & 26.9 & 32.0 & 29.1 \\
\hline Non-cohabiting & 5.3 & 21.0 & 16.8 & 12.6 & 11.8 & 12.0 \\
\hline Single & 21.4 & 41.4 & 42.6 & 39.0 & 29.3 & 30.5 \\
\hline Missing information & 0.3 & & & & & 0.0 \\
\hline \multicolumn{7}{|l|}{ Number of siblings } \\
\hline 0 & 5.7 & 6.4 & 5.2 & 5.8 & 5.1 & 5.2 \\
\hline 1 & 19.8 & 20.4 & 34.2 & 35.7 & 38.3 & 35.7 \\
\hline 2 & 17.0 & 28.0 & 25.2 & 31.0 & 33.0 & 31.1 \\
\hline 3 & 14.8 & 15.3 & 18.7 & 11.5 & 12.9 & 13.2 \\
\hline 4 or more & 42.8 & 29.9 & 16.8 & 15.9 & 10.7 & 14.8 \\
\hline Missing information & & & & 0.3 & & 0.0 \\
\hline Full final sample (n) & 318 & 157 & 155 & 364 & 2,938 & 3,932 \\
\hline
\end{tabular}

Source: own calculations based on Wave 1 of the Swedish Generations and Gender Survey (GGS) 


\section{Comparative Population Studies}

WWW.comparativepopulationstudies.de

ISSN: 1869-8980 (Print) - 1869-8999 (Internet)

\section{Published by}

Prof. Dr. Norbert F. Schneider

Federal Institute for Population Research D-65180 Wiesbaden / Germany

\section{(cc) BY-SA}

2018

\section{Managing Editor}

Dr. Katrin Schiefer

\section{Copy Editor}

Dr. Evelyn Grünheid

Dr. Katrin Schiefer

\section{Editorial Assistant}

Beatriz Feiler-Fuchs

Wiebke Hamann

\section{Layout \\ Beatriz Feiler-Fuchs \\ E-mail:cpos@bib.bund.de}

\section{Scientific Advisory Board}

Karsten Hank (Cologne)

Michaela Kreyenfeld (Berlin)

Marc Luy (Vienna)

Peter Preisendörfer (Mainz)

Nikola Sander (Wiesbaden)

Zsolt Spéder (Budapest)

Rainer Wehrhahn (Kiel)

\section{Board of Reviewers}

Martin Abraham (Erlangen)

Laura Bernardi (Lausanne)

Hansjörg Bucher (Bonn)

Claudia Diehl (Konstanz)

Andreas Diekmann (Zurich)

Gabriele Doblhammer-Reiter (Rostock)

Jürgen Dorbritz (Wiesbaden)

Anette Eva Fasang (Berlin)

E.-Jürgen Flöthmann (Bielefeld)

Alexia Fürnkranz-Prskawetz (Vienna)

Beat Fux (Salzburg)

Joshua Goldstein (Berkeley)

Sonja Haug (Regensburg)

Hill Kulu (Liverpool)

Aart C. Liefbroer (The Hague)

Kurt Lüscher (Konstanz)

Emma Lundholm (Umeå)

Nadja Milewski (Rostock)

Dimiter Philipov (Vienna)

Roland Rau (Rostock)

Tomáš Sobotka (Vienna)

Jeroen Spijker (Barcelona)

Olivier Thévenon (Paris)

Helga de Valk (Brussels)

Heike Trappe (Rostock)

Michael Wagner (Cologne) 